

\title{
III. ESPAÑA, BREXIT Y GIBRALTAR. DECLARACIONES, COMUNICADOS Y NOTAS DE PRENSA (2018-2020)
}

\author{
Inmaculada GONZÁLEZ GARCÍA*; Alejandro DEL VALLE GÁLVEZ; \\ Lorena CALVO MARISCAL; Juan Domingo TORREJÓN RODRÍGUEZ
}

\section{Documentación incluida en este apartado:}

DOCUMENTO 1. Comunicado del Consejo Europeo. Declaraciones interpretativas obtenidas por España con motivo del Consejo Europeo que refrendó el Tratado de Retirada de Noviembre 2018, 25 de noviembre de 2018.

DOCUMENTO 2. Declaración del Presidente de Gobierno: «España ha alcanzado un acuerdo sobre Gibraltar. Europa y Reino Unido han aceptado nuestras exigencias», 24 de noviembre de 2018.

DOCUMENTO 3. Comunicado 171. Valor jurídico de las declaraciones en relación a Gibraltar (Brexit), 27 noviembre 2018.

DOCUMENTO 4. Comunicado 172. Firma de los memorandos entre España y el Reino Unido sobre Gibraltar, 29 noviembre 2018.

DOCUMENTO 5. Comunicado 041. España firma con el Reino Unido un Tratado fiscal sobre Gibraltar, 4 marzo 2019.

DOCUMENTO 6. Nota de prensa 139. Nueva reunión técnica entre España y el Reino Unido sobre el Brexit, 2 octubre 2019.

* Esta Sección se enmarca en el Proyecto de Investigación financiado por la Fundación Pública Andaluza Centro de Estudios Andaluces (PRY205/19): "La incidencia del 'Brexit' en la cooperación transfronteriza entre Gibraltar-Campo de Gibraltar y Andalucía”, coordinado por la Profesora Inmaculada González García. Período de vigencia, 2020-2022. 
DOCUMENTO 7. Nota de prensa 003. Reunión preparatoria España-Reino Unido para puesta en marcha de los comités previstos en los Memorándums de Entendimiento de 29 de noviembre de 2018, 23 enero 2020.

DOCUMENTO 8. Nota de prensa 015. Reunión de la ministra de Asuntos Exteriores, Unión Europea y Cooperación con las Autoridades del Campo de Gibraltar, 21 febrero 2020.

DOCUMENTO 9. Nota de prensa 019. Primeras reuniones de las comisiones previstas en los Memorándums firmados por España y Reino Unido sobre Gibraltar, 27 febrero 2020.

DOCUMENTO 10. Nota de prensa 079. Primera reunión del comité especializado sobre Gibraltar previsto en el Protocolo sobre Gibraltar del Acuerdo de Retirada de Reino Unido de la Unión Europea, 27 mayo 2020.

DOCUMENTO 11. Nota de prensa 85. Primera ronda de conversaciones entre España y Reino Unido sobre el futuro de la relación de Gibraltar con España y la UE, 9 junio 2020.

DOCUMENTO 12. Nota de prensa 109. Segunda reunión de la comisión de coordinación prevista en el Memorándum de derechos de los ciudadanos firmado por España y Reino Unido sobre Gibraltar, 9 julio 2020.

DOCUMENTO 13. Nota de prensa 125. Segundas reuniones de las comisiones de coordinación previstas en los Memorándums de Entendimiento sobre cooperación policial y aduanera, y en materia medioambiental firmados por España y el Reino Unido sobre Gibraltar, 29 julio 2020.

DOCUMENTO 14. Nota de prensa 132. Segunda ronda de negociación entre el Reino Unido y España sobre la relación Post-Brexit de Gibraltar con la UE, 3 septiembre 2020.

DOCUMENTO 15. Nota de prensa 187. Acuerdo sobre los trabajadores transfronerizos del Campo de Gibraltar, 17 de noviembre de 2020.

DOCUMENTO 16. Comunicado del Servicio de Información de Gibraltar. El Gobierno publica una guía para trabajadores transfronterizos de la UE, EEE y Suiza, 17 de noviembre de 2020. 


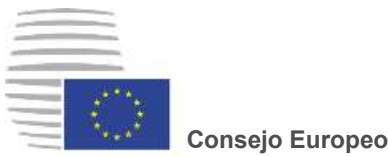

Bruselas, 25 de noviembre de 2018

(OR. en)

EUCO XT 20017/18

BXT 117

CO EUR 29

\begin{tabular}{ll} 
NOTA & \\
\hline De: & $\begin{array}{l}\text { Secretaría General del Consejo } \\
\text { Delegaciones }\end{array}$ \\
\hline A: & $\begin{array}{l}\text { Reunión extraordinaria del Consejo Europeo (Art. 50) } \\
\text { (25 de noviembre de 2018) } \\
\end{array}$ \\
& - Declaraciones para el acta
\end{tabular}

Adjunto se remiten a las delegaciones ${ }^{1}$ las Declaraciones que habrán de constar en el acta de la reunión del Consejo Europeo (Art. 50) del 25 de noviembre de 2018, tal como han sido aprobadas.

1 Tras efectuar una notificación con arreglo al artículo 50 del TUE, el miembro del Consejo Europeo que representa al Estado miembro que se retira no participará ni en las deliberaciones ni en las decisiones del Consejo Europeo que le afecten. 


\section{Declaración relativa al Acuerdo de Retirada y a la Declaración Política}

La Unión ha negociado y celebrará el Acuerdo de Retirada a la luz de las orientaciones facilitadas por el Consejo Europeo de conformidad con el artículo 50 del Tratado de la UE. El Consejo Europeo seguirá dando las orientaciones políticas necesarias en relación con la aplicación del Acuerdo.

Sobre la base de sus sucesivas Orientaciones de 29 de abril de 2017, 15 de diciembre de 2017 y 23 de marzo de 2018, el Consejo Europeo prestará especial atención a la salvaguardia de los derechos e intereses de los ciudadanos, a la necesidad de mantener unas condiciones de competencia equitativas ambiciosas y a la protección de las empresas pesqueras y las comunidades costeras.

Lo hará tanto al evaluar la aplicación del Acuerdo de Retirada, si se ha de poner en funcionamiento la solución de último recurso, como a la hora de considerar las relaciones futuras, en particular en el ámbito del medio ambiente en lo referente a la alineación con las normas europeas.

Como se recuerda en el Acuerdo de Retirada, es prioritario un acuerdo de pesca; este acuerdo debe basarse, entre otros elementos, en el marco existente en materia de acceso recíproco existente y reparto de cuotas. Dicho acuerdo debe negociarse mucho antes de que expire el periodo transitorio.

El Consejo Europeo y la Comisión Europea acogen con satisfacción los compromisos, reafirmados en la Declaración Política, con los acuerdos internacionales de lucha contra el cambio climático, en particular con el Acuerdo de París, así como los compromisos que abarcan, entre otras cuestiones, el cambio climático, a partir de las disposiciones sobre condiciones de competencia equitativas previstas en el Acuerdo de Retirada. Habida cuenta de ello, la retirada del Reino Unido de la Unión no afectará a los compromisos compartidos con arreglo al Acuerdo de París.

Cuando la posición que haya de adoptar el Comité Mixto haga referencia a la prórroga del período transitorio y a la revisión del Protocolo sobre Irlanda/Irlanda del Norte, el Consejo actuará de acuerdo con las orientaciones del Consejo Europeo. Cualquier decisión sobre la prórroga del período transitorio tendrá en cuenta el cumplimiento por parte del Reino Unido de las obligaciones derivadas del Acuerdo, incluidos sus Protocolos.

EUCO XT 20017/18 
En lo concerniente a las negociaciones de acuerdos que regulen las relaciones futuras con el Reino Unido las directrices de negociación se elaborarán sobre la base de las orientaciones previamente acordadas por el Consejo Europeo.

El Consejo Europeo suscribe las declaraciones que constan en el acta de la sesión del Consejo de Asuntos Generales (Art. 50) celebrada el 20 de marzo de 2018.

\section{Declaración interpretativa del Consejo Europeo (Art. 50) y de la Comisión Europea sobre el artículo 184 del Acuerdo de Retirada}

El único objetivo del artículo 184 del Acuerdo de Retirada es crear una obligación de medios para que la Unión y el Reino Unido negocien acuerdos que regulen sus relaciones futuras. No impone obligación alguna respecto del ámbito de aplicación territorial de dichos acuerdos. Por lo tanto, no hay obligación ni presunción algunas fundamentadas en esta disposición de que dichos acuerdos tengan el mismo ámbito de aplicación territorial que el que establece el artículo 3 del Acuerdo de Retirada.

El Consejo Europeo y la Comisión Europea toman nota de la declaración del Reino Unido y de que el Reino Unido comparte la presente interpretación.

\section{Declaración del Consejo Europeo (Art. 50) y de la Comisión Europea sobre el ámbito de aplicación territorial de los futuros acuerdos}

Una vez que el Reino Unido haya abandonado la Unión, Gibraltar no estará incluido en el ámbito de aplicación territorial de los acuerdos que se celebren entre la Unión y el Reino Unido. Ello no excluye, sin embargo, la posibilidad de que se celebren acuerdos separados entre la Unión y el Reino Unido respecto de Gibraltar. Sin perjuicio de las competencias de la Unión y en pleno respeto de la integridad territorial de sus Estados miembros garantizada por el artículo 4, apartado 2, del Tratado de la Unión Europea, dichos acuerdos separados requerirán un acuerdo previo del Reino de España. 


\title{
DOC
}

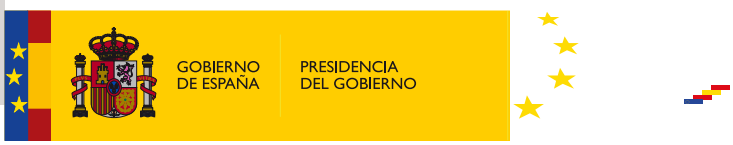

Comparecencia del presidente del Gobierno, Pedro Sánchez

\section{Sánchez: "España ha alcanzado un acuerdo sobre Gibraltar. Europa y Reino Unido han aceptado nuestras exigencias"}

Palacio de la Moncloa, Madrid, sábado 24 de noviembre de 2018

\begin{abstract}
El presidente del Gobierno, Pedro Sánchez, ha comparecido esta tarde ante los medios de comunicación para anunciar que España ha alcanzado un acuerdo sobre Gibraltar que supone "un triple blindaje con el que puede abordar definitivamente con el Reino Unido el futuro del peñón en los próximos años".

Contenido íntegro de su declaración:
\end{abstract}

Buenas tardes, acabo de anunciar al Jefe del Estado, al Rey, que España ha alcanzado un acuerdo sobre Gibraltar. Lo primero que quiero decirles es que el Consejo Europeo, en consecuencia, se va a celebrar en el día de mañana, y lo segundo es que Europa y el Reino Unido han aceptado las exigencias que había marcado España y por tanto en consecuencia España levantará el veto y votará mañana a favor del Brexit.

Antes de explicar el contenido de dicha solución, quisiera compartir los motivos por los cuales el Gobierno de España en estos días se ha opuesto al Brexit. La cuestión de Gibraltar es capital para España, la integridad territorial, la soberanía nacional, son elementos presentes en la identidad de nuestro país, por eso defendemos los intereses nacionales y hemos sido firmes y determinados en la defensa de los intereses generales.

Gibraltar no es solo un territorio por descolonizar, tal y como reconoce el derecho internacional y Naciones Unidas, sino que desde el ingreso de España en la Comunidad Económica Europea allá por el año 86, Gibraltar ha experimentado un crecimiento europeo muy importante, que ha llevado a que esté entre la primeras economías del mundo en renta per cápita. Esto se debe a la conjunción de varios aspectos, en primer lugar a un régimen de excepción con respecto a la legislación británica, dado que pertenece al Reino Unido, y en segundo lugar al acceso al mercado interior de la Unión Europea. Esto ha provocado consecuencias negativas para la zona circundante, el campo de Gibraltar, quien haya estado en la zona podrá comprobar perfectamente cuales son las enormes diferencias entre el campo de Gibraltar y Gibraltar. Y para el Gobierno la prosperidad y el progreso del campo de Gibraltar también es un tema de Estado, además de la soberanía nacional y de la integridad territorial.
MÁS INFORMACIÓN

Galería fotográfica 
Aspiramos, sin duda alguna, a una relación futura con los gibraltareños fructífera, estrecha, ambiciosa, que favorezca el desarrollo equilibrado, subrayo equilibrado, de Gibraltar y del campo de Gibraltar, y a una prosperidad conjunta en consecuencia.

El tercer anuncio que quiero trasladar es que una vez que la retirada del Reino Unido se produce de la Unión Europea, la relación de Gibraltar con la Unión Europea, la relación política, jurídica y hasta geográfica pasarán por España.

Por tanto, interés nacional es la prosperidad conjunta entre Gibraltar y el campo de Gibraltar y España como pilar fundamental de lo que va representar la relación futura con el conjunto de la Unión Europea.

A continuación paso a detallarles las garantías que exigía España y que hemos logrado en estas difíciles negociaciones, pero fructíferas negociaciones. En primer lugar, y por primera vez en la historia, hemos logrado una declaración conjunta del Consejo Europeo y de la Comisión Europea, en el marco del Acuerdo de Retirada, que descarta que el artículo 184, el artículo en discordia que teníamos el Gobierno de España con el Reino Unido, sea aplicable al contenido de la relación futura, incluida, y esto es lo importante, en el ámbito territorial.

Segundo, el Gobierno británico reconoce por escrito esta interpretación, el Gobierno de España le da un valor trascendental al reconocimiento por escrito por parte del gobierno británico de esta cuestión.

En tercer lugar, en el marco de la declaración política futura, el Consejo Europeo y la Comisión Europea refuerzan la posición de España y la refuerzan como nunca había estado de cara a las negociaciones futuras, que son las más transcendentales que vamos a tener porque vamos a tener que hablar de la cosoberanía y de otras cosas con el Reino Unido. Por un lado, porque la declaración recoge que no solo se deberá contar con el acuerdo de España, sino que los acuerdos que afecten a Gibraltar, deberán ser acuerdos separados a los que se concluyan con el Reino Unido por parte de la Unión Europea, y por otro hemos obtenido una declaración política conjunta del Consejo Europeo y de la Comisión Europea que es un texto histórico, sienta las bases por escrito de una nueva forma de abordar la relación con Gibraltar a nivel europeo.

Los aspectos más importantes de esta declaración son los siguientes:

En primer lugar excluye a Gibraltar de la negociación general entre la Unión Europea y el Reino Unido. Esto va a permitir a España tener una negociación directa con el Reino Unido sobre Gibraltar.

Segundo, exige el acuerdo previo de España para la negociación de cualquier acuerdo de la Unión Europea que se aplique a Gibraltar. Con ello, garantizamos que los ámbitos de negociación futura en la relación con Gibraltar sean de nuestro interés y acordes con nuestra política en relación con Gibraltar.

No estamos hablando ya de una aplicación o de un acuerdo, sino de una 
verdadera elaboración política hacia Gibraltar que incluya la dimensión europea.

Se refiere específicamente a la obligación de respetar, y esto es importante, la integridad territorial de los Estados, uno de los fundamentos más importantes de la reclamación del Gobierno de España durante estas últimas horas.

Este es un elemento político y jurídico transcendental para que España haya podido acordar los extremos de este acuerdo, porque incorpora de manera específica lo establecido en el art. 4.2 del Tratado de la Unión Europea, y con ello queda claro que el problema de la integridad territorial de España es un elemento esencial a preservar y a tener en cuenta por el Consejo Europeo y por la Comisión Europea.

Es también una declaración de la Comisión, no sólo de los estados miembros, lo que es esencial, no solo por su calidad de guardiana de los tratados de la Unión Europea, sino también por su responsabilidad a la hora de negociar cualquier tratado con terceros, incluido de forma especial el que se negocie con Reino Unido.

En tercer lugar, el Gobierno de España logra una carta conjunta de los presidentes de la Comisión Europea y el Consejo Europeo, ratificando las exigencias españolas.

En definitiva, para que se entienda, España logra un triple blindaje, un triple blindaje histórico, con el que puede abordar definitivamente con el Reino Unido el futuro de Gibraltar durante los próximos años.

Con este triple blindaje, se refuerza significativamente lo establecido en anteriores etapas, como las orientaciones del Consejo Europeo aprobadas en el año 2017.

Antes de concluir, quisiera decir varias cosas:

La primera de ellas como decía al principio, he informado al Rey del acuerdo alcanzado. En segundo lugar, durante el fin de semana el ministro de Asuntos Exteriores se va a poner en contacto con todos los portavoces de exteriores de los distintos grupos parlamentarios en el Congreso de los Diputados. Yo haré lo propio la próxima semana con todos los grupos parlamentarios y también, lógicamente con el grupo mixto. También, compareceré el día 12 de diciembre, ante el Congreso de los Diputados para explicar los extremos de este acuerdo y también los extremos del Consejo Europeo a celebrar en el día de mañana.

Y finalmente, quiero trasladar varios mensajes, el primero de ellos a la población del Campo de Gibraltar. Que durante estos últimos días han vivido con zozobra y con auténtica preocupación el bloqueo que se ha producido durante estas últimas horas. El Gobierno de España siembre va a velar por sus intereses, económicos y sociales.

Al conjunto de españoles quisiera trasladarles que hemos dado un paso decisivo, determinado, un paso adelante, y que estamos con las garantías absolutas para resolver un conflicto que dura más de 300 años. Hemos logrado las garantías suficientes para poder abordar la solución a un conflicto que dura más de 300 años, entre el Reino Unido y España. 
Y finalmente al pueblo británico, decirle que España quiere seguir manteniendo las mejores relaciones con el Reino Unido. Son muchos españoles los que viven en el Reino Unido y son muchos los británicos que viven también en nuestro país.

Y no quiero acabar sin agradecer a los presidentes del Consejo y de la Comisión Europea y a los colegas del Consejo Europeo, a todos los estados miembros, su apoyo y su comprensión sobre esta cuestión, que para nosotros ha sido transcendental.

Y por último a nuestro equipo de diplomáticos, al equipo de abogados del Estado, a los negociadores tanto en Bruselas como en España, porque sin ellos este éxito diplomático no hubiera sido posible.

Tenemos un gran Estado, unos grandes servidores públicos, y somos un gran país.

Gracias 
III. España, Brexity Gibraltar. Declaraciones, Comunicados y Notas de Prensa (2017-2020)

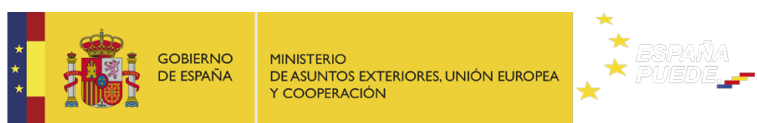

Ministerio Política exterior y cooperación Servicios al ciudadano Sala de prensa

Está usted en: INICIO > SALA DE PRENSA > COMUNICADOS

\section{Actualidad}

$>$ España y Senegal refuerzan su cooperación

$>$ Siete nuevos embajadores presentan credenciales a Su Majestad el Rey

$>$ Concluye la semana inaugural del $75^{\circ}$ período de sesiones de la Asamblea General

> Arancha González Laya visita Jordania
COMUNICADO 171

\section{Valor jurídico de las declaraciones en relación a Gibraltar (Brexit)}

\section{$27 / 11 / 2018$}

En relación con algunas afirmaciones aparecidas en distintos medios de comunicación poniendo en duda el valor jurídico de las declaraciones interpretativas suscritas el pasado domingo por la Unión Europea y sus Estados miembros por una parte y el Reino Unido por otra, referidas al artículo 184 del Acuerdo de Retirada del Reino Unido de la UE, el Ministerio de Asuntos Exteriores, Unión Europea y Cooperación desea recordar lo siguiente: 


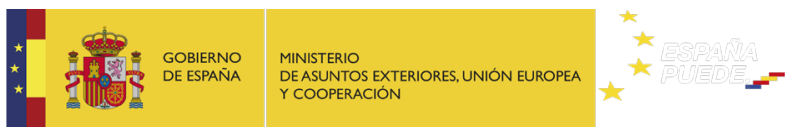

\section{Actualidad}

$>$ España y Senegal refuerzan su cooperación

$>$ Siete nuevos embajadores presentan credenciales a Su Majestad el Rey

$>$ Concluye la semana inaugural del $75^{\circ}$ período de sesiones de la Asamblea General

> Arancha González Laya visita Jordania

\title{
COMUNICADO 172 \\ Firma de los memorandos entre España y el Reino Unido sobre Gibraltar
}

\section{$29 / 11 / 2018$}

El Ministro de Asuntos Exteriores, Unión Europea y Cooperación ha firmado hoy por parte de España los cuatro memorandos bilaterales que están referenciados en el Protocolo sobre Gibraltar anejo al Acuerdo de Retirada del Reino Unido de la Unión Europea. Se trata de acuerdos sobre derechos de los ciudadanos, tabaco y otros productos, cooperación en materia medioambiental y cooperación policial y aduanera. Por parte del Reino Unido ha firmado el Ministro del gabinete, David Lidington.

En el marco de la salida del Reino Unido de la Unión y con arreglo a las Orientaciones que la propia UE dio en su momento, España emprendió hace casi un año negociaciones con el Reino Unido para lograr que la salida de Gibraltar fuera lo más ordenada posible y beneficiosa para los intereses españoles. El objetivo del gobierno español en este proceso ha sido garantizar los derechos de los trabajadores de la zona y paliar los desequilibrios socioeconómicos existentes a ambos lados de la Verja. Después de duras negociaciones ha habido un acuerdo satisfactorio para España.

\begin{abstract}
Estos cuatro memorandos aparecen mencionados en el Protocolo sobre Gibraltar anejo al Acuerdo de Retirada, que firman la UE y el Reino Unido, y que fue aprobado por el Consejo Europeo del pasado 25 de noviembre. Se trata de la primera vez que aparecen en el derecho básico de la Unión Europea unas disposiciones relativas a Gibraltar negociadas por España. El Protocolo es, por tanto, parte de un acuerdo UEReino Unido, mientras que los memorandos enfocan los mismos temas desde una perspectiva bilateral Reino Unido-España. Además, los acuerdos bilaterales alcanzados sobre Gibraltar se completarán con un acuerdo internacional sobre fiscalidad y protección de intereses financieros.
\end{abstract}

El acuerdo sobre ciudadanos permite unas modalidades específicas de ejecución para los trabajadores transfronterizos en Gibraltar de los derechos y garantías que el Acuerdo de Retirada otorga a los ciudadanos y trabajadores en general. Así, se garantizan los derechos de los trabajadores del Campo de Gibraltar, incluyendo sus beneficios sociales, que disfrutarán en igualdad de condiciones que los locales conforme al principio de no discriminación. Se prevén, además, mecanismos de coordinación y el intercambio de información entre autoridades para garantizar su efectivo cumplimiento. Asimismo, las autoridades británicas se han comprometido a 
DOCUMENTACIÓN

III. España, Brexit y Gibraltar. Declaraciones, Comunicados y Notas de Prensa (2017-2020)

$23 / 11 / 2020$

4
Firma de los memorandos entre España y el Reino Unido sobre Gibralta

reembolsar a la Hacienda española la diferencia en las prestaciones por desempleo adelantadas por España a trabajadores trasfronterizos.

En relación con el tabaco, el Protocolo y el MoU establecen obligaciones de control de mercado gibraltareño y de trazabilidad de los productos del tabaco que deberán implantarse antes de 2020, para lo que se prevén las oportunas medidas de coordinación e intercambio de información. Asimismo, antes del final del período transitorio, en junio de 2020 , las autoridades gibraltareñas deberán reducir el precio de los productos de tabaco para que la diferencia de precios con los españoles no sea superior al $32 \%$. Todas estas medidas son fundamentales para la lucha contra el contrabando de este producto y su entrada ilegal en nuestro país, con los consiguientes efectos que ello tiene en la seguridad de la zona y en la recaudación fiscal.

En materia medioambiental, el MoU establece el principio de cooperación para asegurar los máximos estándares de protección en toda la zona, con las consecuencias que de ello se deriva en cuestiones como la gestión de los residuos sólidos y líquidos, el control del suministro de combustible a embarcaciones o la investigación científica, incluida la investigación marina a través de buques destinados a tal efecto.

Con el objetivo de mejorar la situación de la seguridad y frenar la delincuencia en la región, se ha acordado asimismo un texto en materia de cooperación policial y aduanera que permite reforzar los sistemas de coordinación entre autoridades policiales de la zona de forma que pueda mejorar la colaboración en la investigación y persecución de toda una serie de delitos, en particular aquellos que afectan en mayor medida a esta área, como son el narcotráfico o la lucha contra el tráfico de personas. Se incluyen, por primera vez, entre los ámbitos de la cooperación, los delitos relacionados con la seguridad vial y las investigaciones en materia de delitos financieros, así como la coordinación en el ámbito aduanero, que permitirá la lucha contra el contrabando y el tráfico de drogas, amparando, en su caso, la posibilidad de que se colabore en operaciones conjuntas.

Respecto al acuerdo sobre fiscalidad y protección de intereses financieros, ya se ha llegado a un acuerdo sobre su contenido y la tramitación para su firma se iniciará a la mayor brevedad posible. Al afectar su contenido a materias propias de reserva legal es necesario que se firme en un acuerdo internacional, que requerirá aprobación parlamentaria.

Este acuerdo fiscal será el primero que firme España con Reino Unido para garantizar que la jurisdicción fiscal de Gibraltar es transparente con nuestras autoridades fiscales y no puede ser utilizada para el blanqueo de capitales o la evasión fiscal. Es un tema tan importante que se ha preferido un tratado internacional a pesar de la dificultad en negociarlo. En materia fiscal, las autoridades gibraltareñas establecerán un sistema reforzado de cooperación administrativa con España para luchar contra el fraude, el contrabando y el blanqueo de dinero y garantizar la plena transparencia fiscal en Gibraltar. El acuerdo, además, fija unos criterios de residencia fiscal para evitar la evasión fiscal. En definitiva, supone un paso adelante para que Gibraltar no pueda constituirse como un paraíso fiscal que permita soslayar las obligaciones tributarias con la Hacienda española.

El conjunto de estos acuerdos garantizan una salida ordenada de Gibraltar de la Unión Europea, incluyendo el periodo transitorio. Se producirá en unas condiciones que garantizan los derechos de los ciudadanos y trabajadores de la zona y que además empiezan a corregir los principales desequilibrios de la relación entre Gibraltar y el 
INMACULADA GONZÁLEZ GARCÍA; ALEJANDRo DEL VALLE GÁLVEZ;

LORENA CALVO MARISCAL ; JUAN DOMINGO TORREJÓN RODRÍGUEZ;

$23 / 11 / 2020$

Firma de los memorandos entre España y el Reino Unido sobre Gibraltar

DOC

Campo de Gibraltar. El gobierno español considera que crean confianza para todos y demuestran la virtud del método de ir avanzando progresivamente sobre bases

sólidas. Marca el camino a seguir en la próxima negociación sobre una nueva relación de Gibraltar con España y la UE en el marco de lo que se ha acordado en el Consejo Europeo del pasado día 25. 


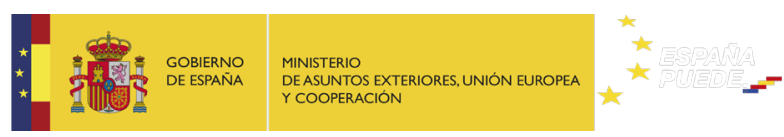

Ministerio Política exterior y cooperación Servicios al ciudadano Sala de prensa

Está usted en: INICIO > SALA DE PRENSA > COMUNICADOS

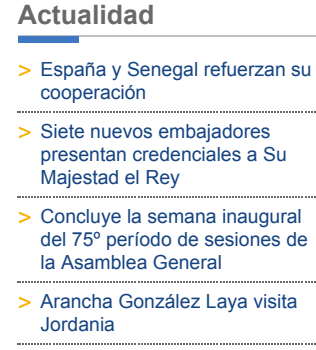

COMUNICADO 041

\section{España firma con el Reino Unido un Tratado fiscal sobre Gibraltar}

\section{$04 / 03 / 2019$}

El Ministro de Asuntos Exteriores, Unión Europea y Cooperación ha firmado hoy "Ad referéndum" un Acuerdo Internacional en materia de fiscalidad y protección de los intereses financieros entre el Reino de España y el Reino Unido de la Gran Bretaña e Irlanda del Norte. Por parte del Reino Unido el Acuerdo será firmado hoy por el Ministro de la Presidencia, David Lidington.

Este Acuerdo tiene rango de Tratado Internacional y es el primer Tratado que España firma con el Reino Unido sobre Gibraltar desde el Tratado de Utrecht, firmado en 1713 El citado Acuerdo se firma en el marco de la salida del Reino Unido de la Unión Europea. La firma "Ad referéndum" requiere su aprobación por el Consejo de Ministros. Además por razón de la materia este Tratado está sujeto a la correspondiente aprobación parlamentaria.

Como es sabido, la Unión Europea ha negociado un Acuerdo de Retirada que incluye un protocolo anejo sobre Gibraltar fruto de la negociación entre el Reino Unido y España. Dicho Protocolo menciona los cuatro memorandos de entendimiento sobre Gibraltar firmados el pasado 21 de Noviembre (sobre derecho de los ciudadanos, tabaco, cooperación en materia ambiental y cooperación en materia policial y aduanera), así como el Acuerdo Fiscal firmado hoy por el Ministro Josep Borrell y que ha sido negociado bilateralmente con el Reino Unido.

Este Acuerdo constituye una pieza esencial para que la salida de Gibraltar de la Unión Europea con arreglo al Acuerdo de Retirada y a su Protocolo sobre Gibraltar tenga lugar de manera ordenada y conforme a los intereses españoles en materia fiscal y de lucha contra el fraude y la evasión de impuestos.

Aún en el caso de una salida del Reino Unido de la Unión Europea sin acuerdo, al no firmarse el Acuerdo de Retirada, el tratado fiscal sigue siendo igualmente útil pues asegura a España un alto grado de cooperación de las autoridades fiscales competentes cuando el derecho de la Unión Europea deje de aplicarse en Gibraltar.

Los objetivos que se han alcanzado con el mismo son:

- La reducción y eliminación del fraude fiscal y los efectos perjudiciales para la hacienda española derivados de las características del régimen fiscal de Gibraltar. 
- El establecimiento de unas reglas claras para resolver más fácilmente los conflictos de residencia fiscal de las personas físicas.

- Evitar la utilización de sociedades sujetas al régimen fiscal de Gibraltar por residentes fiscales en España o para la realización de actividades económicas en España.

Para ello, el Acuerdo establece un régimen reforzado de cooperación administrativa entre las autoridades competentes de las respectivas administraciones tributarias. Este régimen incluye el intercambio de información sobre determinadas categorías de rentas y activos de especial importancia para la lucha contra el fraude en la zona. Asimismo, se prevé la adaptación dinámica de este régimen especial de cooperación a los nuevos estándares de la Unión Europea y la OCDE en materia de transparencia cooperación administrativa, prácticas fiscales perjudiciales y de lucha contra el blanqueo de capitales.

El acuerdo establece además una serie de normas para resolver los conflictos de residencia fiscal de las personas físicas, con el objetivo de resolver los problemas de falsas residencias en Gibraltar de personas físicas que residen realmente en España.

Respecto a las Personas jurídicas y otras entidades gibraltareñas, se establece su residencia fiscal en España cuando las mismas tengan una relación significativa con España, bien por la localización de la mayoría de sus activos o la obtención de la mayor parte de sus ingresos en nuestro país, o bien cuando la mayoría de sus propietarios o su directivos son residentes fiscales en España. 


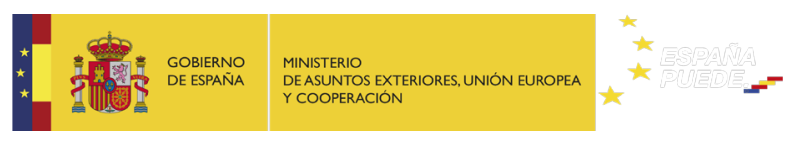

\section{Actualidad}

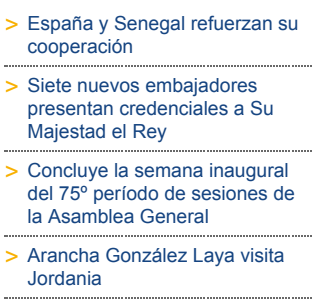

\section{NOTA DE PRENSA 139 \\ Nueva reunión técnica entre España y Reino Unido sobre el Brexit}

\section{$02 / 10 / 2019$}

Como continuación de los contactos que el MAEC viene manteniendo con la administración británica sobre este asunto, se ha celebrado hoy, en la sede del Ministerio de Asuntos Exteriores, Unión Europea y Cooperación en Madrid, una nueva reunión a nivel técnico sobre el Brexit. España es partidaria de una retirada ordenada y considera que un Brexit con acuerdo es la mejor manera de preservar los intereses de los ciudadanos y las empresas. En este sentido, España está siguiendo muy de cerca las conversaciones entre los negociadores británicos y los de la UE en busca de una solución.

En un clima de entendimiento y cooperación, las delegaciones británica y española han repasado hoy el estado de situación del Brexit y han intercambiado informaciones de interés para la adecuada preparación de cada país para una situación de noacuerdo, especialmente en lo tocante a derechos de los ciudadanos, seguridad social y asistencia sanitaria, incluyendo el caso particular de Gibraltar.

España está preparada para una retirada sin acuerdo. La delegación española ha informado a su contraparte británica sobre las medidas legislativas, logísticas y de comunicación que ha aprobado, siguiendo el principio de reciprocidad, para reducir al mínimo el impacto negativo de un Brexit sin acuerdo y ha recibido información sobre los planes de las autoridades británicas en el mismo sentido. 


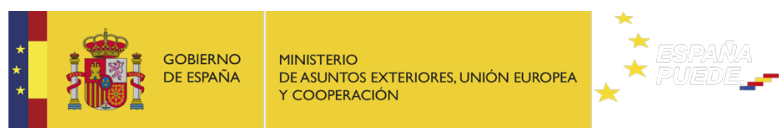

\section{Ministerio Política exterior y cooperación Servicios al ciudadano Sala de prensa}

Está usted en: INICIO > SALA DE PRENSA > NOTAS DE PRENSA

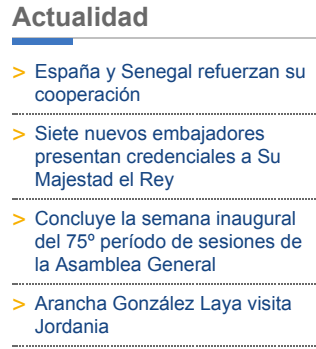

\section{$23 / 01 / 2020$}

Hoy día 23 de enero ha tenido lugar una reunión a nivel técnico para preparar las primeras reuniones de los distintos comités bilaterales previstos en los Memorándums de Entendimiento firmados por España y Reino Unido el 29 de noviembre de 2018 Dichos Memorándums, cuyos efectos se despliegan principalmente en el periodo transitorio, acompañan al Protocolo sobre Gibraltar, anejo al Acuerdo de Retirada del Reino Unido de la Unión Europea.

Los comités previstos en los Memorándums son los siguientes:

- Comisión de Coordinación del Memorándum de derechos de los ciudadanos;

- Comisión de Coordinación Conjunta del Memorándum sobre cooperación policial y aduanera;

- Comisión Técnica y de Coordinación del Memorándum sobre cooperación en materia medioambiental.

La reunión se ha desarrollado en una atmósfera constructiva y de confianza en la que se ha puesto de manifiesto la voluntad de cooperación de todos los participantes. A lo largo de la reunión se han analizado en detalle y se ha avanzado en numerosas cuestiones prácticas relativas a la implementación de los Memorándums, para garantizar los derechos de los ciudadanos y de los trabajadores. Estas cuestiones, que afectan a numerosos aspectos prácticos de la vida en el Campo de Gibraltar, serán tratados en profundidad en los comités previstos al efecto una vez se constituyan. Se ha acordado que las primeras reuniones de los comités tendrán lugar en Algeciras en el próximo mes de febrero y se ha definido también una agenda para dichas reuniones.

En la reunión de hoy han participado por parte española, además del Ministerio de Asuntos Exteriores, Unión Europea y Cooperación, representantes de los Ministerios de Interior, Trabajo y Economía Social, Inclusión, Seguridad Social y Migraciones, Agencia Tributaria, Transición Ecológica y el Reto Demográfico así como el Delegado 


\section{DOCUMENTACIÓN}

III. España, Brexit y Gibraltar. Declaraciones, Comunicados y Notas de Prensa (2017-2020) Andalucía y el Presidente de la Mancomunidad de Municipios del Campo de Gibraltar. Por parte británica han asistido representantes de la Embajada británica en Madrid, del Foreign and Commonwealth Office y de las autoridades gibraltareñas. 


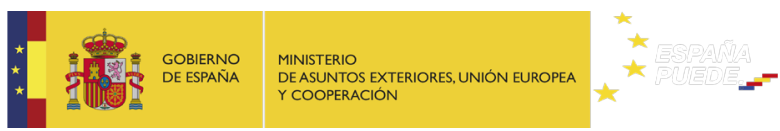

\section{Ministerio Política exterior y cooperación Servicios al ciudadano Sala de prensa}

Está usted en: INICIO > SALA DE PRENSA > NOTAS DE PRENSA

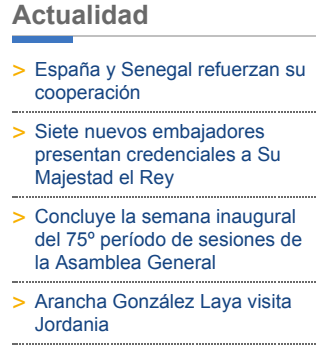

NOTA DE PRENSA 015

Reunión de la ministra de Asuntos
Exteriores, Unión Europea y Cooperación
con las Autoridades del Campo de
Gibraltar

$21 / 02 / 2020$

La ministra de Asuntos Exteriores, Unión Europea y Cooperación, Arancha González Laya, ha recibido en la mañana de hoy, 21 de febrero, en el Palacio de Viana, a las Autoridades locales y autonómicas con competencias en el Campo de Gibraltar, para informarles del estado en que se encuentran las negociaciones con el Reino Unido sobre la salida de éste de la Unión Europea -y, por tanto, de Gibraltar, en cuanto que colonia que el Reino Unido administra-, y de sus consecuencias para el Campo de Gibraltar; así como para escuchar de primera mano las opiniones y preocupaciones que el Brexit suscita en la Administración autonómica andaluza y en las Administraciones locales del Campo de Gibraltar.

La ministra recordó que, si bien Gibraltar va a abandonar la Unión Europea por una decisión del Reino Unido, España ha hecho todo lo posible para asegurar que la salida de Gibraltar de la Unión se haga de manera predecible sin causar perjuicios a la población del Campo de Gibraltar.

En virtud del Acuerdo de Retirada suscrito entre la Unión Europea y el Reino Unido, que entró en vigor el pasado 1 de febrero, y el Protocolo específico sobre Gibraltar, los ciudadanos del Campo de Gibraltar seguirán disfrutando de sus derechos tal como lo han venido haciendo hasta ahora, y durante el periodo transitorio, que se extiende hasta el 31 de diciembre de este año, la vida seguirá igual en el Campo de Gibraltar.

Además, España suscribió con el Reino Unido cuatro memorándums de entendimiento bilaterales sobre medio ambiente, cooperación policial y aduanera, tabaco y otros productos, y derechos de los ciudadanos, el 29 de noviembre de 2018, y un acuerdo en materia fiscal, que permitirá encauzar la salida de Gibraltar de la UE de manera ordenada. En este sentido, la señora ministra se refirió a las primeras reuniones de los Comités Mixtos previstos en los MOUS, que tendrán lugar en Algeciras los días 26 y 27 de febrero.

Próximamente la UE iniciará las negociaciones con el Reino Unido para determinar su 

necesario el consentimiento español para cualquier acuerdo futuro entre el Reino Unido y la UE sobre Gibraltar. La ministra subrayó que los intereses del Campo de Gibraltar estarán en el centro de las negociaciones.

La ministra y las Autoridades locales y autonómicas intercambiaron opiniones más en detalle sobre algunos de estos temas de particular interés para los ciudadanos del Campo de Gibraltar.

La ministra reiteró que una de las prioridades de su Ministerio en las negociaciones sobre la relación futura con el Reino Unido y Gibraltar será la defensa de los intereses de los ciudadanos del Campo de Gibraltar y, muy en particular, de los trabajadores, con el objeto de que la salida del Reino Unido y Gibraltar de la Unión supongan, en último término, una oportunidad para crear una zona de prosperidad compartida.

La reunión se desarrolló en un ambiente constructivo y de transparencia y confianza, que ha puesto de relieve la voluntad de todos los participantes de cooperar de manera efectiva, alineando sus posiciones en defensa de la población del Campo de Gibraltar.

En el encuentro participaron, además del Ministerio de Asuntos Exteriores, Unión Europea y Cooperación, los alcaldes de Algeciras, la Línea de la Concepción, San Roque, Los Barros, Tarifa, Castellar de la Frontera, Jimena de la Frontera y San Martín del Tesorillo, el Secretario General de Acción Exterior de la Junta de Andalucía, la Subdelegación del Gobierno en Andalucía, la Diputación Provincial de Cádiz, y la Mancomunidad de municipios del Campo de Gibraltar. 


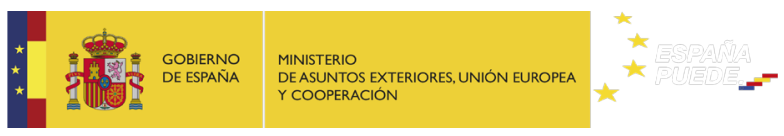

\section{Ministerio Política exterior y cooperación Servicios al ciudadano Sala de prensa}

Está usted en: INICIO > SALA DE PRENSA > NOTAS DE PRENSA

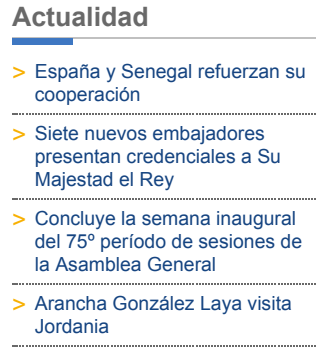

NOTA DE PRENSA 019

Primeras reuniones de las comisiones previstas en los Memorándums firmados por España y Reino Unido sobre Gibraltar

\section{$27 / 02 / 2020$}

Las reuniones constitutivas de las tres comisiones bilaterales previstas en los Memorándums de Entendimiento firmados por España y Reino Unido sobre Gibraltar se han celebrado ayer y hoy en Algeciras en un espíritu de cordial de colaboración.
Los encuentros han permitido avanzar en la coordinación técnica en materias relacionadas con la mejora práctica de la cooperación policial y aduanera con el fin de hacer más efectiva sobre el terreno la lucha contra la criminalidad en la zona, incluyendo el problema del comercio ilícito de tabaco. Se ha repasado, además, el calendario de subidas de precios del tabaco en el marco de los acuerdos alcanzados.

En lo relativo a ciudadanos y trabajadores, se han analizado las medidas prácticas necesarias para que se beneficien plenamente de los derechos reconocidos en el Acuerdo de Retirada, incluyendo las facilidades para su correcta identificación y registro.

Por su parte, la reunión de la Comisión Técnica y de Cooperación (CTC) prevista en e Memorándum de cooperación en materia ambiental, ha sido el foro de análisis e intercambio de información en los aspectos relacionados con el medio ambiente en la zona.

Los Memorándums firmados el 29 de noviembre de 2018, cuyos efectos se despliegan principalmente en el periodo transitorio, acompañan al Protocolo sobre Gibraltar, anejo al Acuerdo de Retirada del Reino Unido de la Unión Europea.

Las comisiones previstas en esos Memorándums son:
- La comisión de coordinación del Memorándum de derechos de los ciudadanos.

- La comisión de coordinación conjunta del Memorándum sobre cooperación policial y aduanera. 
III. España, Brexity Gibraltar. Declaraciones, Comunicados y Notas de Prensa (2017-2020)

$23 / 11 / 2020$

Primeras reuniones de las comisiones previstas en los Memorándums firmados por España y Reino Unido sobre Gibraltar

- La comisión técnica y de coordinación del Memorándum sobre cooperación en materia medioambiental.

En estas reuniones han participado, por parte española, además del Ministerio de Asuntos Exteriores, Unión Europea y Cooperación; representantes de los Ministerios de Interior; Trabajo y Economía Social; Inclusión, Seguridad Social y Migraciones; la Agencia Tributaria; Transición Ecológica y el Reto Demográfico y Transportes, Movilidad y Agenda Urbana, así como la Delegación del Gobierno en Andalucía. También han participado representantes de la Junta de Andalucía y el Presidente de la Mancomunidad de Municipios del Campo de Gibraltar. Por parte británica, han asistido representantes de la Embajada británica en Madrid, del Foreign and Commonwealth Office y de las autoridades gibraltareñas. 


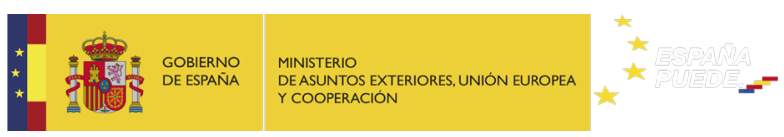

\section{Ministerio Política exterior y cooperación Servicios al ciudadano Sala de prensa}

Está usted en: INICIO > SALA DE PRENSA > NOTAS DE PRENSA

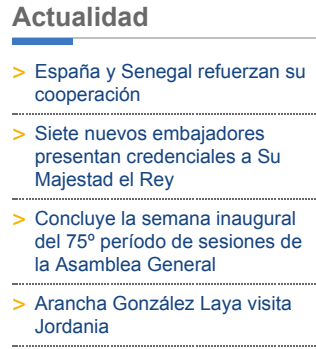

NOTA DE PRENSA 079

Primera reunión del comité especializado sobre Gibraltar previsto en el Protocolo sobre Gibraltar del Acuerdo de Retirada del Reino Unido de la Unión Europea

\begin{abstract}
$27 / 05 / 2020$
Hoy se ha celebrado por videoconferencia la primera reunión del comité especializado sobre Gibraltar previsto en el protocolo sobre Gibraltar del Acuerdo de Retirada del Reino Unido de la Unión Europea. En esta reunión han participado delegaciones de la Unión Europea, incluyendo representantes del MAUC de España, y del gobierno del Reino Unido. El protocolo de Gibraltar fue incluido en el acuerdo de retirada dada la importancia de la zona para la Unión Europea y las especiales características de la misma.
\end{abstract}

Ambas partes han repasado el grado de cumplimiento de las obligaciones contenidas en el Protocolo sobre Gibraltar y en los cuatro memorandos de entendimiento bilaterales suscritos entre España y el Reino Unido en materia de derechos de los ciudadanos, cooperación policial y aduanera, medio ambiente y tabaco.

Más en concreto, en lo relativo a ciudadanos y trabajadores, ambas partes han analizado las medidas prácticas necesarias para que éstos se beneficien plenamente de los derechos reconocidos en el Acuerdo de Retirada, incluyendo las facilidades para su correcta identificación y registro. Así mismo han intercambiado puntos de vista en relación a la obligación de mantener los derechos laborales y de todo tipo de los trabajadores fronterizos y en relación al estado de situación de los reembolsos pendientes de las cantidades adelantadas por España para el pago de las prestaciones por desempleo.

Por otro lado, ambas partes han analizado vías para la mejora práctica de la cooperación policial y aduanera con el fin de hacer más efectiva sobre el terreno la lucha contra la criminalidad en la zona, incluyendo el problema del comercio ilícito de tabaco. Se ha repasado, además, el calendario de subidas de precios del tabaco al que se comprometieron las autoridades gibraltareñas en el marco de los acuerdos alcanzados, que establece la fecha límite del 30 de junio de 2020 para la materialización de dicho compromiso. 
DOCUMENTACIÓN

III. España, Brexit y Gibraltar. Declaraciones, Comunicados y Notas de Prensa (2017-2020)

23/11/2020 Primera reunión del comité especializado sobre Gibraltar previsto en el Protocolo sobre Gibraltar del Acuerdo de Retirada del Rein...

Finalmente, en lo tocante al Acuerdo Internacional en materia de fiscalidad y protección de los intereses financieros entre España y el Reino Unido en relación con Gibraltar ambas partes han intercambiado informaciones sobre el estado de situación de los respectivos procedimientos de ratificación parlamentaria, que ambas partes esperan que puedan concluirse en otoño o antes si es posible.

La Unión Europea y el Reino Unido acordaron que la próxima sesión de este Comité tenga lugar en el mes de noviembre.

Esta reunión demuestra el compromiso por parte de la Unión Europea con el territorio comprendido por los municipios de la Mancomunidad de Municipios del Campo de Gibraltar y la garantía de que en el proceso de retirada del Reino Unido de la UE se van a respetar todos los intereses de la Unión, en particular en materia fiscal, de medio ambiente y de seguridad y, muy especialmente, en lo relativo a derechos de los ciudadanos y trabajadores. 


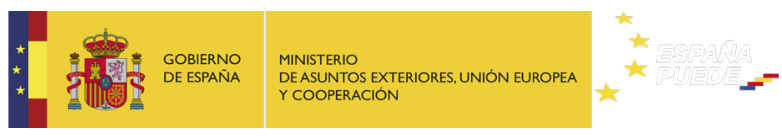

\section{Ministerio Política exterior y cooperación Servicios al ciudadano Sala de prensa}

Está usted en: INICIO > SALA DE PRENSA > NOTAS DE PRENSA

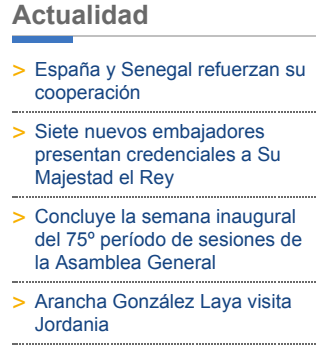

NOTA DE PRENSA 85

Primera ronda de conversaciones entre España y Reino Unido sobre el futuro de la relación de Gibraltar con España y la UE

\begin{abstract}
09/06/2020
Esta mañana se han iniciado en Málaga las conversaciones entre España y el Reino Unido sobre el futuro de la relación de Gibraltar con España y la Unión Europea en el
\end{abstract} contexto de la salida del Reino Unido de la UE.

En esta primera ronda participaron, por parte española una delegación integrada por funcionarios del MAUEC y representantes de otros Ministerios. Por parte británica asistió una delegación compuesta por funcionarios del Foreign Office acompañada de una representación de las autoridades gibraltareñas, encabezada por el Ministro Principal de Gibraltar Fabian Picardo.

Durante la reunión se examinaron las cuestiones que orientarán el curso de las siguientes rondas de las conversaciones entre España y el Reino Unido en relación a Gibraltar que ahora se inician.

Se intercambiaron también puntos de vista sobre el estado de las negociaciones UEReino Unido sobre su relación futura.

Las partes llegaron a un principio de acuerdo sobre el calendario y organización de las siguientes rondas de conversaciones.

Hubo también acercamiento en la definición de los elementos que formarían parte de un eventual acuerdo, entre los que son prioritarios los intereses de los trabajadores y de los ciudadanos de la zona. 


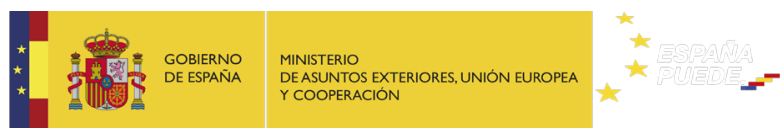

Ministerio Política exterior y cooperación Servicios al ciudadano Sala de prensa

Está usted en: INICIO > SALA DE PRENSA > NOTAS DE PRENSA

\section{Actualidad}

$>$ España y Senegal refuerzan su cooperación

$>$ Siete nuevos embajadores presentan credenciales a Su Majestad el Rey

$>$ Concluye la semana inaugural del $75^{\circ}$ período de sesiones de la Asamblea General

> Arancha González Laya visita Jordania
NOTA DE PRENSA 109

\section{Segunda reunión de la comisión de coordinación prevista en el Memorándum de derechos de los ciudadanos firmado por España y Reino Unido sobre Gibraltar}

\section{9/07/2020}

La segunda reunión de la comisión bilateral prevista en el Memorando de Entendimiento sobre los derechos de los ciudadanos firmado por España y Reino Unido en relación con Gibraltar se ha celebrado hoy en Gibraltar en un espíritu de cordial colaboración. Al igual que en la primera reunión celebrada en Algeciras el pasado 26 de febrero, el contenido del encuentro ha sido eminentemente técnico y ha permitido avanzar en las medidas prácticas necesarias para que ciudadanos y trabajadores se beneficien plenamente de los derechos reconocidos en el Acuerdo de Retirada.

El Memorando de Entendimiento sobre los derechos de los ciudadanos, firmado el 29 de noviembre de 2018, junto con el Memorando sobre cooperación policial y aduanera, el Memorando sobre cooperación en materia medioambiental y el Memorando sobre el tabaco y otros productos acompañan al Protocolo sobre Gibraltar, anejo al Acuerdo de Retirada del Reino Unido de la Unión Europea y despliega sus efectos más allá del periodo transitorio previsto en el propio Acuerdo de Retirada.

Esta segunda reunión fue aplazada por causa de la crisis sanitaria de la COVID-19 y ha sido retomada tan pronto como ha sido posible. En la misma han participado, por parte española, además del Ministerio de Asuntos Exteriores, Unión Europea y Cooperación, representantes del Ministerio del Interior, del Ministerio de Trabajo y Economía Social y del Ministerio de Inclusión, Seguridad Social y Migraciones. También han participado representantes de la Junta de Andalucía y el Presidente de la Mancomunidad de Municipios del Campo de Gibraltar. Por parte británica, han asistido representantes de la Embajada del Reino Unido en Madrid, del Foreign and Commonwealth Office y de las autoridades gibraltareñas. 


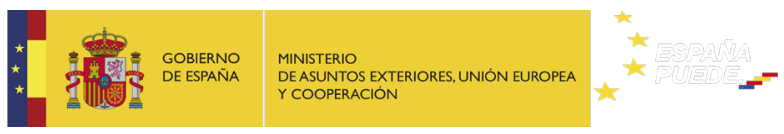

\begin{tabular}{|c|c|}
\hline \multicolumn{2}{|r|}{ Actualidad } \\
\hline \multicolumn{2}{|r|}{$\begin{array}{l}>\text { España y Senegal refuerzan su } \\
\text { cooperación }\end{array}$} \\
\hline & $\begin{array}{l}\text { Siete nuevos embajadores } \\
\text { presentan credenciales a Su } \\
\text { Majestad el Rey }\end{array}$ \\
\hline & $\begin{array}{l}\text { Concluye la semana inaugural } \\
\text { del } 75^{\circ} \text { período de sesiones de } \\
\text { la Asamblea General }\end{array}$ \\
\hline & $\begin{array}{l}\text { Arancha González Laya visita } \\
\text { Jordania }\end{array}$ \\
\hline
\end{tabular}

\begin{abstract}
$29 / 07 / 2020$
Ayer 28 de julio de 2020 se reunieron en Gibraltar las comisiones de coordinación establecidas en los Memorándums de Entendimiento sobre cooperación policial y aduanera, y sobre asuntos medioambientales, firmados por España y el Reino Unido en relación con Gibraltar el 29 de noviembre de 2018. Es la segunda ocasión en que ambas comisiones se reúnen. El primer encuentro tuvo lugar los pasados días 26 y 27 de febrero de este año, respectivamente, y han tenido continuidad ahora, tan pronto como las restricciones impuestas por la epidemia del Covid-19 lo han permitido.
\end{abstract}

Las reuniones se han celebrado en un clima de cordialidad y de voluntad de colaboración entre ambas partes, y han tenido, como las anteriores, un carácter eminentemente técnico.

\begin{abstract}
La Comisión de Coordinación Conjunta sobre cooperación policial y aduanera tuvo lugar por la mañana, y en ella se han examinado las conclusiones de los dos Grupos de Trabajo, sobre temas policiales y aduaneros respectivamente, que se reunieron el pasado 2 de julio en Gibraltar. En la Comisión se trataron aspectos prácticos y operativos de dicha cooperación, con el fin de hacer más efectiva la lucha contra la criminalidad en la zona. Fueron tratados asimismo los aspectos ligados a la implementación del Memorándum de Entendimiento sobre el tabaco y otros productos, constatándose avances positivos en este sentido.

En horario de tarde se reunió la Comisión Técnica y de Cooperación (CTC), del Memorandum de Entendimiento de Cooperación en materia ambiental. En ella se pasó revista a los resultados de la primera reunión de la comisión celebrada el 27 de febrero y se profundizó en aspectos de interés común relativos al medio ambiente en la zona. Las comisiones previstas en esos Memorándums son:
\end{abstract}


DOCUMENTACIÓN

III. España, Brexit y Gibraltar. Declaraciones, Comunicados y Notas de Prensa (2017-2020)

$23 / 11 / 2020$ Segundas reuniones de las comisiones de coordinación previstas en los Memorándums de Entendimiento sobre cooperación polici..

- La Comisión de Coordinación del Memorándum de derechos de los ciudadanos.

- La Comisión de Coordinación Conjunta del Memorándum sobre cooperación policial y aduanera.

- La Comisión Técnica y de Coordinación del Memorándum sobre cooperación en materia medioambiental.

Por parte española participaron en la reunión de la Comisión de Coordinación Conjunta sobre cooperación policial y aduanera representantes del Ministerio de Asuntos Exteriores, Unión Europea y Cooperación, de la Agencia Tributaria y del Ministerio del Interior, así como de la Delegación del Gobierno en Andalucía. En la CTC la delegación española estuvo integrada por representantes del Ministerio de Asuntos Exteriores, Unión Europea y Cooperación, del Ministerio del Interior, del Ministerio para la Transición Ecológica y el Reto Demográfico, del Ministerio de Transportes, Movilidad y Agenda Urbana, así como de la Junta de Andalucía y el Presidente de la Mancomunidad de Municipios del Campo de Gibraltar. Por parte británica, han asistido representantes del Foreign and Commonwealth Office y de las autoridades gibraltareñas. 


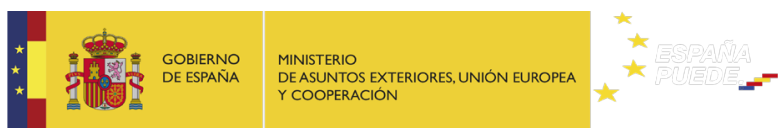

\section{Ministerio Política exterior y cooperación Servicios al ciudadano Sala de prensa}

Está usted en: INICIO > SALA DE PRENSA > NOTAS DE PRENSA

\section{Actualidad}

$>$ España y Senegal refuerzan su cooperación

$>$ Siete nuevos embajadores presentan credenciales a Su Majestad el Rey

$>$ Concluye la semana inaugural del $75^{\circ}$ período de sesiones de la Asamblea General

$>$ Arancha González Laya visita Jordania

\section{NOTA DE PRENSA 132 \\ Segunda ronda de negociación entre el Reino Unido y España sobre la relación Post-Brexit de Gibraltar con la Unión Europea}

\begin{abstract}
03/09/2020
Hoy ha tenido lugar en Madrid la segunda ronda de conversaciones entre Reino Unido y España sobre la relación post-Brexit entre los dos países, con especial atención a Gibraltar. Las conversaciones, teniendo siempre como prioridad el bienestar de los ciudadanos y trabajadores, cubren una amplia variedad de asuntos que deberán ser resueltos para conseguir una relación fuerte, saludable y equilibrada en el área del Campo de Gibraltar, incluyendo movilidad de personas y trabajadores, transporte, bienes y servicios, policía y aduanas, medio ambiente, fiscalidad y otras provisiones sobre igualdad de oportunidades (level playing field).
\end{abstract}

Mañana tendrá lugar una reunión en Londres donde se abordarán cuestiones de seguridad y defensa.

En las conversaciones ha participado una delegación británica compuesta por representantes del Foreign Commonwealth and Development Office y de la oficina del Primer Ministro, acompañada de una representación de las autoridades gibraltareñas encabezadas por el ministro principal de Gibraltar.

Por parte española han participado funcionarios del Ministerio de Asuntos Exteriores, UE y Cooperación; Interior; Hacienda, Integración, Seguridad Social y Migraciones; Transporte, Movilidad y Agenda Urbana y Transición Ecológica y Reto Demográfico. 


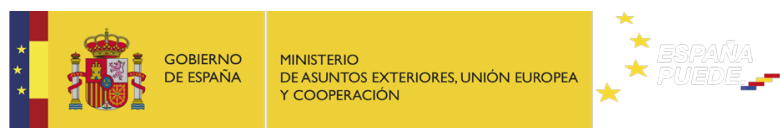

Ministerio Política exterior y cooperación Servicios al ciudadano Sala de prensa

Está usted en: INICIO > SALA DE PRENSA > NOTAS DE PRENSA

\section{Actualidad}

$>$ España y Senegal refuerzan su cooperación

$>$ Siete nuevos embajadores presentan credenciales a Su Majestad el Rey

$>$ Concluye la semana inaugural del $75^{\circ}$ período de sesiones de la Asamblea General

> Arancha González Laya visita Jordania

\section{NOTA DE PRENSA 187 \\ Acuerdo sobre los trabajadores fronterizos del Campo de Gibraltar}

\section{$17 / 11 / 2020$}

Las autoridades de España, Reino Unido y Gibraltar han acordado el procedimiento para que los 15.000 residentes de la Unión Europea que trabajan en Gibraltar, de los que casi 10.000 son españoles, puedan hacer efectivos sus derechos a partir del 1 de enero de 2021. Por parte española, han intervenido en las reuniones la Mancomunidad de Municipios del Campo de Gibraltar, la Junta de Andalucía y la Administración General del Estado.

El Acuerdo de Retirada entre el Reino Unido y la Unión Europea garantizó a los trabajadores fronterizos el mantenimiento de todos los derechos laborales de que disfrutaban antes del Brexit en virtud de la legislación de la Unión Europa. España incluyó un Protocolo sobre Gibraltar en dicho Acuerdo de Retirada y firmó con el Reino Unido un memorándum sobre derechos de los ciudadanos y trabajadores con el fin de reforzar este aspecto del Brexit. Desde su entrada en vigor, las tres administraciones han negociado cómo aplicar esos derechos a quienes entran todos los días en Gibraltar para trabajar.

A partir del 1 de Diciembre, los trabajadores fronterizos podrán verificar en una web de las autoridades gibraltareñas si están registrados como tales. A partir del 1 de Enero de 2021, podrán asimismo pedir si lo desean a las autoridades de Gibraltar una carta que certifique su condición laboral. La carta sólo se expedirá a quien la solicite.

SI algún trabajador no aparece como fronterizo y estima que tiene derecho a ello, podrá dirigirse a las autoridades gibraltareñas exponiendo su caso.

Las autoridades de Gibraltar expondrán los detalles del procedimiento en una publicación.

Los trabajadores podrán acreditar su identidad en cualquier momento y al entrar en Gibraltar con su pasaporte y DNI españoles o de otro país de la Unión Europea.

Desde el 1 de Enero, y mientras mantengan tal condición, los trabajadores fronterizos recibirán el tratamiento a que ya tienen derecho según la legislación de la Unión Europea, a pesar del Brexit. 
INMACULADA GONZÁLEZ GARCÍA; ALEJANDRo DEL VALLE GÁLVEZ; LORENA CALVO MARISCAL ; JUAN DOMINGo TORREJÓN RODRÍGUEZ; había dado lugar el Brexit en el Campo de Gibraltar y en Gibraltar.

Las partes seguirán reuniéndose para analizar cualquier cuestión que surja en coordinación con la Comisión Europea como guardiana de los tratados de la Unión Europea y de su correcta aplicación. 


\section{INFOGIBRALTAR}

SERVICIO DE INFORMACIÓN DE GIBRALTAR

COMUNICADO

\section{Gobierno de Gibraltar}

El Gobierno publica una guía para trabajadores transfronterizos de la UE, EEE y Suiza

Gibraltar, 17 de noviembre de 2020

El Gobierno ha publicado hoy una nueva Nota Técnica para servir como guía a los trabajadores transfronterizos procedentes de la UE, EEE (Espacio Económico Europeo) y Suiza que trabajan en Gibraltar y viven en España. El EEE comprende Noruega, Islandia y Liechtenstein.

El Acuerdo de Retirada firmado por el Reino Unido y la Unión Europea establecía los derechos que retendrían los ciudadanos británicos, incluyendo los gibraltareños, que trabajasen al otro lado de la frontera, en la Unión Europea, y los ciudadanos de la UE que trabajasen en el Reino Unido y Gibraltar. Esta reciprocidad también se extiende a ciudadanos del EEE y Suiza.

La última guía establece claramente que únicamente las personas registradas como trabajadores transfronterizos a fecha 31 de diciembre de 2020 podrán ejercer sus derechos según el Acuerdo de Retirada. También se establece un mecanismo para que las personas puedan comprobar si estarían cualificadas como tales a partir del 1 de diciembre de 2020.

La naturaleza reciproca de este acuerdo implica que cualquier ciudadano británico, incluyendo los gibraltareños, que viva en Gibraltar y trabaje en la Unión Europea, en concreto en España, debería adoptar medidas para familiarizarse con los procedimientos de registro en dicho país y registrase correctamente.

La noticia se acompaña de la Nota Técnica 


\section{(1NFOG IBRALTAR}

SERVICIO dE INFORMACIÓN DE GIBRALTAR

COMUNICADO

\section{Nota a redactores:}

Esta es una traducción realizada por el Servicio de Información de Gibraltar. Algunas palabras no se encuentran en el documento original y se han añadido para mejorar el sentido de la traducción. El texto válido es el original en inglés.

Para cualquier ampliación de esta información, rogamos contacte con Servicio de Información de Gibraltar

Miguel Vermehren, Madrid, miguel@infogibraltar.com, Tel 609004166 Sandra Balvín, Campo de Gibraltar, sandra@infogibraltar.com, Tel 637617757 Eva Reyes Borrego, Campo de Gibraltar, eva@infogibraltar.com, Tel 619778498

Web: www.infogibraltar.com, web en inglés: www.gibraltar.gov.gi/press Twitter: @InfoGibraltar 


\section{Nota técnica (11)}

Preparación para el final del período de transición

17 de noviembre de 2020

\section{Guía para trabajadores transfronterizos de la UE, EEE y Suiza}

El Acuerdo de Retirada firmado entre la Unión Europea y el Reino Unido estableció los términos de la retirada ordenada del Reino Unido y Gibraltar de la UE.

El Acuerdo de Retirada, que se aplica igualmente a Gibraltar, entró en vigor el 1 de febrero de 2020.

El 31 de diciembre de 2020, el Periodo de Transición establecido según el Acuerdo de Retirada llegará a su fin. El final del Periodo de Transición pondrá fin al actual status quo. Con sujeción al resultado de las actuales negociaciones relativas a la futura relación de Gibraltar con la UE, los cambios resultantes afectarán principalmente a personas que no estén cubiertas por el alcance personal del Acuerdo de Retirada y que deseen ejercer sus derechos en Gibraltar a partir del 1 de enero de 2021.

\section{Propósito}

El objetivo del Acuerdo de Retirada, en lo que se refiere a los Derechos de los Ciudadanos, es salvaguardar y preservar derechos derivados de la normativa comunitaria que sean ejercidos, a partir del 31 de diciembre de 2020, por ciudadanos de la UE, EEE o Suiza en el Reino Unido y Gibraltar, así como ciudadanos británicos, incluyendo gibraltareños, en la UE, EEE o Suiza.

El propósito de esta Nota Técnica es explicar a los trabajadores transfronterizos residentes en España que trabajen en Gibraltar a 31 de diciembre de 2020, los mecanismos que está implementando el Gobierno de Gibraltar para preservar sus derechos comunitarios en Gibraltar. Estos trabajadores transfronterizos podrán, pasado el 31 de diciembre de 2020, continuar trabajando en Gibraltar y podrán beneficiarse de los mismos derechos comunitarios de los que disfrutan en la actualidad.

Esta Nota Técnica cubre únicamente la posición de los trabajadores transfronterizos procedentes de la UE, EEE o Suiza. El 16 de noviembre de 2020 se emitió una Nota Técnica aparte, relativa a los ciudadanos de la UE, EEE o Suiza que buscasen ejercer el derecho de residencia en Gibraltar.

\section{¿Qué trabajadores transfronterizos están cubiertos por el Acuerdo de Retirada?}

\section{Personas que trabajan}

Una persona estará considerada como trabajador transfronterizo cubierto por el Acuerdo de Retirada si cumple con los siguientes requisitos a fecha 31 de diciembre de 2020:

(1) Ciudadano de la UE, EEE o Suiza;

(2) No residente en Gibraltar; 
(3) Y además:

(a) Un trabajador empleado que trabaje legalmente en Gibraltar con un contrato de empleo; o

(b) Un trabajador autónomo que desempeñe legalmente una actividad en Gibraltar y donde Gibraltar sea el lugar de establecimiento. Para que Gibraltar se considere como el lugar de establecimiento será necesario que el centro de interés de las actividades del trabajador autónomo se encuentre en Gibraltar y se vea sujeto a la legislación sobre seguridad social de Gibraltar.

\section{Personas que no trabajan}

En el caso de personas que, habiendo trabajado en Gibraltar, ya no sean empleados o trabajadores autónomos desempeñando su actividad en Gibraltar, se considerará que retienen su condición de trabajadores transfronterizos en Gibraltar, y por tanto cubiertos por el Acuerdo de Retirada, siempre que, a fecha 31 de diciembre de 2020, cumplan los siguientes requisitos:

(1) Con incapacidad temporal para trabajar como resultado de enfermedad o accidente;

(2) En situación de desempleo involuntario debidamente registrada tras haber estado empleado en Gibraltar durante al menos un año;

(3) En situación de desempleo involuntario debidamente registrada tras haber estado empleado en Gibraltar durante menos de un año (dichas personas solamente retendrán su condición de trabajador transfronterizo cubierto por el Acuerdo de Retirada durante un máximo de 6 meses);

(4) En situación de desempleo involuntario y habiendo iniciado formación vocacional;

(5) En situación de desempleo voluntario y habiendo iniciado formación vocacional relacionada con el anterior empleo de esa persona; o

(6) Con incapacidad temporal para trabajar debido a embarazo o parto 3 .

\section{¿Cuáles son los beneficios para los trabajadores transfronterizos cubiertos por el Acuerdo de} Retirada?

Tal y como se estipula anteriormente, los trabajadores transfronterizos cubiertos por el Acuerdo de Retirada podrán, más allá del 31 de diciembre de 2020, continuar trabajando en Gibraltar y podrán beneficiarse de los mismos derechos comunitarios de los que disfrutan actualmente.

En la práctica, esto significa que los trabajadores transfronterizos cualificados continuarán teniendo los mismos derechos laborales basados en la normativa comunitaria de los que actualmente disfrutan. Esto incluye derecho a la no discriminación, derecho a emprender una actividad en Gibraltar y derecho a ventajas sociales y fiscales. Por lo tanto, por ejemplo, los trabajadores transfronterizos cualificados mantendrán las mismas condiciones que han existido hasta ahora con respecto a los beneficios de desempleo.

\footnotetext{
${ }^{1}$ Una persona satisface este párrafo cuando haya proporcionado pruebas de que continúa buscando empleo o trabajo autónomo en Gibraltar.

${ }^{2}$ Una persona satisface este párrafo cuando haya proporcionado pruebas de que continúa buscando empleo o trabajo autónomo en Gibraltar.

${ }^{3}$ Una persona satisface este párrafo cuando, 12 meses después de dejar de trabajar y en lo subsiguiente, proporcione pruebas de que continúa buscando empleo o trabajo autónomo en Gibraltar.
} 

de Retirada?

El Gobierno de Gibraltar ha mantenido, y continuará manteniendo, datos precisos sobre las personas registradas como trabajadores transfronterizos en Gibraltar y personas registradas en Gibraltar como en situación de desempleo involuntario. Por lo tanto, el Gobierno ya cuenta con una lista de todos los trabajadores transfronterizos. Las personas que quedarán protegidas por los términos del Acuerdo de Retirada son aquellas cuyos nombres figuren en dicha lista a fecha 31 de diciembre de 2020.

El 1 de diciembre de 2020, el Gobierno lanzará una plataforma online para que estas personas puedan verificar su estatus. A partir de esa fecha, podrá visitarse la web frontierworkers.egov.gi. Una vez se encuentre operativa, la plataforma permitirá introducir detalles identificativos de una persona para confirmar si se encuentra, o no, "en proceso" para ser considerada persona cubierta por los términos del Acuerdo de Retirada a partir del 31 de diciembre de 2020.

A partir del 1 de enero de 2021, los trabajadores transfronterizos que realicen una búsqueda en la plataforma online recibirán una confirmación definitiva respecto a su condición, o no, como trabajadores transfronterizos cubiertos por los términos del Acuerdo de Retirada. Esta información será proporcionada mediante una respuesta automática. De forma independiente, a partir del 1 de enero de 2021, los trabajadores transfronterizos también tendrán la posibilidad de contactar con el Departamento de Empleo (Department of Employment) de Gibraltar para obtener una carta que certifique que son trabajadores transfronterizos cubiertos por los términos del Acuerdo de Retirada. Podrá contactarse con el Departamento para este fin mediante los siguientes canales:

Correo postal: Department of Employment

Employment Registration Section

Unit 75 Harbours Walk

New Harbours

Gibraltar

Email: $\quad$ frontierworkers@gibraltar.gov.gi

Teléfono: $\quad$ (00350) 20011050 o 20011024

En aquellos casos en los que el estatus de una persona como trabajador transfronterizo en Gibraltar sea certificado mediante su inclusión en la lista electrónica mantenida por el Departamento de Empleo de Gibraltar no será obligatorio que los trabajadores transfronterizos obtengan una copia de dicha carta.

A partir del 1 de enero de 2021, todos los departamentos y agencias del Gobierno que tengan la necesidad de saber si una persona es un trabajador transfronterizo cubierto por los términos del Acuerdo de Retirada contarán con acceso electrónico a la lista y a información relativa a cada individuo. Además del propio Departamento de Empleo, esto incluirá a la Agencia de Fronteras y Guardacostas (Borders and Coastguard Agency), Agencia Tributaria (Income Tax Office), Departamento de Seguridad Social (Department for Social Security) y la Autoridad Sanitaria de Gibraltar (Gibraltar Health Authority). Esto permitirá a los trabajadores transfronterizos establecer 
sus derechos según el Acuerdo de Retirada al interactuar con los diversos departamentos del Gobierno en Gibraltar.

Se proporcionarán medios para que aquellas personas que el sistema indique que no son trabajadores transfronterizos cubiertos por los términos del Acuerdo de Retirada, puedan contactar con los departamentos relevantes del Gobierno con el objetivo de corregir su estatus si creen que cumplen las condiciones necesarias. Los trabajadores transfronterizos podrán, más allá del 31 de diciembre de 2020, apelar una decisión adoptada por el Gobierno que consideren errónea.

Importante: Se recuerda a los trabajadores transfronterizos que el factor que determinará si cuentan, o no, con derechos según el Acuerdo de Retirada será el cumplimiento de las condiciones para ser considerados como tales, a fecha 31 de diciembre de 2020 . Una vez cumplidos los pasos establecidos en la siguiente sección "¿Qué deben hacer los trabajadores transfronterizos que actualmente trabajan en Gibraltar antes del 31 de diciembre de 2020?, los trabajadores transfronterizos no necesitarán realizar más acciones.

\section{Controles de Inmigración.}

Al igual que en el Reino Unido, durante un periodo de gracia desde el 1 de enero de 2021 hasta el 1 de julio de 2021, el Gobierno de Gibraltar no impondrá ninguna nueva condición de entrada para que los ciudadanos de la UE, EEE o Suiza (incluyendo trabajadores transfronterizos) puedan entrar en Gibraltar. El Gobierno mantendrá esta posición bajo constante revisión, especialmente dadas las actuales negociaciones para establecer un nuevo régimen de fluidez fronteriza con la UE.

\section{¿Qué deben hacer los trabajadores transfronterizos que actualmente trabajan en Gibraltar antes} del 31 de diciembre de 2020?

Los trabajadores transfronterizos, tanto empleados como trabajadores autónomos, deberán asegurarse de estar correctamente registrados con el Departamento de Empleo de Gibraltar y la Agencia Tributaria de Gibraltar.

Se recuerda a los empleadores que deseen iniciar una relación laboral formal con un trabajador, que deberán presentar Términos de Relación (Terms of Engagement). Podrá contactarse con el Departamento de Empleo de Gibraltar para este fin mediante los siguientes canales:

Email: employment.officers@gibraltar.gov.gi;

WhatsApp: +350 54083175; o

Teléfono: (00350) 20011061, 20011063, 20011000

Aquellas personas que ya no trabajen en Gibraltar y deseen mantener su estatus laboral en Gibraltar (ver sección anterior sobre "Personas que no trabajan"), deberán tomar medidas para registrar formalmente su situación de desempleo y registrarse como en búsqueda de empleo con el Departamento de Empleo de Gibraltar. Esto podrá hacerse mediante los siguientes canales:

Email: findajob.employment@gibraltar.gov.gi;

WhatsApp: +350 54083189; o

Teléfono: (00350) 20011030, 20052662, 20011093. 
Se deberá entregar la siguiente documentación:

(i) Formulario de Registro de Desempleo (Unemployment Registration Form) debidamente completado;

(ii) Prueba de identidad (pasaporte o tarjeta de identidad nacional validos); y

(iii) Para ciudadanos de la UE, EEE o Suiza residentes en España, el Departamento también requerirá un Informe de Vida Laboral emitido por la oficina de empleo relevante en España.

\section{Ciudadanos británicos (incluyendo gibraltareños) trabajando en España como trabajadores transfronterizos.}

Tal y como se establece en las secciones anteriores, el Acuerdo de Retirada salvaguarda, hasta el mismo punto, los derechos comunitarios con los que actualmente cuentan los ciudadanos británicos, incluyendo gibraltareños, que trabajan en España como trabajadores transfronterizos. El Gobierno de España ha manifestado que publicará información para orientar a estas personas acerca de los pasos que deberán adoptar con respecto a las Autoridades españolas para poder establecer su estatus como trabajadores transfronterizos en España.

Al igual que en el caso de personas que trabajan en Gibraltar como trabajadores transfronterizos, se insta a aquellas personas que trabajan en España como trabajadores transfronterizos a que se aseguren de estar registrados con las Autoridades españolas relevantes. Esto les permitirá continuar ejerciendo sus derechos comunitarios en España, según el Acuerdo de Retirada. 


\section{PRESS RELEASE}

No: $811 / 2020$

Date: 17th November 2020

\section{Government issues guidance for EU, EEA and Swiss frontier workers}

The Government has today published a new Technical Notice which serves as guidance to frontier workers from the EU, the EEA and Switzerland who work in Gibraltar and live in Spain. The EEA states are Norway, Iceland and Liechtenstein.

The Withdrawal Agreement which was concluded between the United Kingdom and the European Union set out the rights that would be retained by British Citizens, including Gibraltarians, who are frontier workers in the European Union and by EU nationals who are frontier workers in the United Kingdom and in Gibraltar. This reciprocity also extends to EEA nationals and to Swiss citizens.

The latest guidance makes it clear that only persons registered as frontier workers on 31 December 2020 will be able to exercise rights under the Withdrawal Agreement. It sets out a mechanism for persons to be able to check whether they would qualify as such as from 1 December 2020.

The reciprocal nature of this means that any British Citizens, including Gibraltarians, who live in Gibraltar and who work in the European Union, namely in Spain, should take steps to familiarise themselves with the registration procedures there and should register accordingly.

\section{ENDS}




\title{
Technical Notice (11)
}

\section{Guidance to EU/ EEA and Swiss Frontier Workers}

17 November 2020

\author{
The position under the EU-UK Withdrawal Agreement of Frontier Workers \\ residing in Spain and working in Gibraltar and Frontier Workers residing in \\ Gibraltar and working in Spain.
}

Note: This Guidance Note is purely informative and it does not supplement or complete the EU-UK Withdrawal Agreement or legislation enacted by HM Government of Gibraltar to give effect to the same. For these reasons, this Guidance Note should not be interpreted as stating the official position of HM Government of Gibraltar.

\section{Introduction.}

The Withdrawal Agreement concluded between the European Union and the United Kingdom established the terms of the United Kingdom and Gibraltar's orderly withdrawal from the EU.

The Withdrawal Agreement, which equally applies to Gibraltar, entered into force on 1 February 2020.

On 31 December 2020, the Transition Period established under the Withdrawal Agreement will come to an end. The end of the Transition Period will bring an end to the current status quo. Subject to the outcome of ongoing negotiations concerning Gibraltar's future relationship with the EU, the resulting changes will primarily affect persons who are not covered by the personal scope of the Withdrawal Agreement and who intend to exercise rights in Gibraltar as from 1 January 2021. 


\section{Purpose.}

The objective of the Withdrawal Agreement, in so far as Citizens' Rights are concerned, is to safeguard and preserve rights derived from EU law that are, on 31 December 2020, being exercised by EU, EEA or Swiss citizens in the United Kingdom and Gibraltar and by British nationals, including Gibraltarians, in the EU, the EEA or Switzerland.

The purpose of this Guidance Note is to explain, to frontier workers residing in Spain and working in Gibraltar on 31 December 2020, what mechanisms are being put in place by the Gibraltar Government in order to preserve their EU rights in Gibraltar. Such frontier workers will, beyond 31 December 2020, continue to be able to work in Gibraltar and they will be able to benefit from the same EU rights that they currently enjoy.

This guidance note covers only the position of EU, EEA or Swiss frontier workers. A separate Guidance Note was issued on 16 November 2020 with respect to EU, EEA or Swiss citizens exercising residence rights in Gibraltar.

\section{Who are the frontier workers covered by the Withdrawal Agreement?}

\section{Persons who are working}

A person is a frontier worker covered by the Withdrawal Agreement if on 31 December 2020 they are:

(1) An EU, EEA or Swiss citizen;

(2) Not resident in Gibraltar;

(3) and either:

(a) an employed worker legally working in Gibraltar with a contract of employment; or

(b) a self-employed person legally pursing an activity in Gibraltar where Gibraltar is their place of establishment. In order for Gibraltar to be 
considered the place of establishment it will be necessary for selfemployed persons to have the centre of interest of their activities in Gibraltar and be subject to Gibraltar social security legislation.

\section{Persons who are not working}

A person who, having been working in Gibraltar, is no longer a worker or a selfemployed person working in Gibraltar, will be treated as having retained the status of a frontier worker in Gibraltar and will therefore be covered by the Withdrawal Agreement if, on 31 December 2020, they are:

(1) temporarily unable to work as the result of an illness or accident;

(2) in duly recorded involuntary unemployment after having been employed in Gibraltar for at least one year ${ }^{1}$;

(3) in duly recorded involuntary unemployment after having been employed in Gibraltar for less than one year (such persons shall only retain the status of a frontier worker covered by the Withdrawal Agreement for a maximum of 6 months) $)^{2}$;

(4) in involuntary unemployment having embarked on vocational training;

(5) in voluntary unemployment having embarked on vocational training that is related to the person's previous employment; or

(6) temporarily unable to work due to pregnancy or childbirth ${ }^{3}$.

What are the benefits for frontier workers who are covered by the Withdrawal Agreement?

As stated above, frontier workers covered by the Withdrawal Agreement will, beyond 31 December 2020, continue to be able to work in Gibraltar and they will be able to benefit from the same EU rights that they currently enjoy.

\footnotetext{
A person satisfies this paragraph where they have provided evidence that they continue to seek employment or self-employment in Gibraltar.

2 A person satisfies this paragraph where they have provided evidence that they continue to seek employment or self-employment in Gibraltar.

A person satisfies this paragraph where, 12 months after ceasing work and thereafter, they provide evidence that they continue to seek employment or self-employment in Gibraltar.
} 
In practice, this means that qualifying frontier workers will continue to have the same EU law based workers' rights that they currently enjoy. This includes rights not to be discriminated against, rights to take up and pursue an activity in Gibraltar and rights to social and tax advantages. Therefore, for instance, with respect to unemployment benefits, the same arrangements that have existed up to now will be maintained for qualifying frontier workers.

How will frontier workers be identified as frontier workers covered by the Withdrawal Agreement?

HM Government of Gibraltar has maintained, and will continue to maintain, accurate records with respect to persons registered in Gibraltar as frontier workers and of persons recorded in Gibraltar as being in involuntary unemployment. Therefore, the Government already has a list of all frontier workers. Those who will be protected by the terms of the Withdrawal Agreement are those whose names appear on that list on 31 December 2020.

In order for such persons to be able to verify their status the Government will, on 1 December 2020, be launching an online platform for this purpose. The website will, as of that date, be able to be accessed on frontierworkers.egov.gi. Once it is up and running the platform will, upon persons entering identification details, confirm whether or not they are "on course" to be persons covered by the scope of the Withdrawal Agreement on 31 December 2020.

As from 1 January 2021, frontier workers who interrogate the online platform will receive definitive confirmation as to whether or not they are frontier workers covered by the scope of the Withdrawal Agreement. This will be provided by way of an automated reply. Separately, as from 1 January 2021, frontier workers will also have the possibility of contacting the Gibraltar Department of Employment to obtain a letter certifying that they are frontier workers covered by the scope of the Withdrawal Agreement. The Department will be able to be contacted for these purposes via the following: 


\section{DOC

By Post: Department of Employment

Employment Registration Section

Unit 75 Harbours Walk

New Harbours

Gibraltar

By Email: $\quad$ frontierworkers@gibraltar.gov.gi

By Telephone: 20011050 or 20011024

In circumstances where what will establish a frontier workers' status in Gibraltar will be their inclusion in the electronic list kept by the Gibraltar Department of Employment it will not be mandatory for frontier workers to obtain a copy of this letter.

As from 1 January 2021, all Government departments and agencies that are likely to need to know whether a person is a frontier worker covered by the scope of the Withdrawal Agreement will have electronic access to the list and to information with respect to each individual. In addition to the Department of Employment itself, this will include the Borders and Coastguard Agency, the Income Tax Office, the Department for Social Security and the Gibraltar Health Authority. This is what will allow frontier workers to establish that they have rights under the Withdrawal Agreement when interacting with different Government departments in Gibraltar.

For persons for which the system indicates that they are not frontier workers covered by the scope of the Withdrawal Agreement, facilities will be provided for them to contact relevant Government departments to correct their position if they believe that they meet the conditions to be covered. Frontier workers will be able to, beyond 31 December 2020, challenge a decision which they consider to have been erroneously taken by the Government.

Important: Frontier workers are reminded that what will determine whether or not they have rights under the Withdrawal Agreement is whether, on 31 December 2020, they meet the conditions for being treated as such. Subject to the steps set out in the section below on "what should frontier workers currently 
working in Gibraltar do before 31 December 2020? having been taken, frontier

workers are not required to take any further action.

\section{Immigration Controls.}

As in the UK, during a period of grace from 1 January 2021 to 1 July 2021, HMGoG will not impose any new entry conditions for EU, EEA or Swiss nationals (including frontier workers) to be able to enter Gibraltar. HMGoG will keep this position under review especially in light of the ongoing negotiations to agree a new border fluidity regime with the EU.

What should frontier workers currently working in Gibraltar do before 31 December 2020?

Frontier workers, both employed and self-employed, should ensure that they are duly registered with the Gibraltar Department of Employment and the Gibraltar Income Tax Office.

Employers who wish to formally engage a worker are reminded that they will need to submit Terms of Engagement. For these purposes, the Gibraltar Department of Employment can be contacted:

By Email on: employment.officers@gibraltar.gov.gi;

By WhatsApp on: +350 54083175; or

By Telephone on: 20011061, 20011063, 20011000

For those who are no longer working in Gibraltar and wish to retain worker status in Gibraltar (see section above on "Persons who are not working"), steps should be taken to formally record their unemployment and register as jobseekers with the Gibraltar Department of Employment. This can be done:

By Email on: findajob.employment@gibraltar.gov.gi;

By WhatsApp on: +350 54083189; or

By Telephone on: 20011030, 20052662, 20011093. 


\section{DOC

The following documentation will be required to be submitted:

(i) A duly completed Unemployment Registration Form;

(ii) Proof of identity (a valid passport or national ID card); and

(iii) For EU, EEA or Swiss nationals resident in Spain, the Department will also require a "Vida Laboral" issued by the relevant Spanish employment office.

British nationals (including Gibraltarians) working in Spain as frontier workers.

As set out above, the Withdrawal Agreement safeguards, to the same extent, the EU rights currently being exercised by British nationals, including Gibraltarians, working in Spain as frontier workers. The Government of Spain has stated that it will publish information advising such persons of the steps that would need to be taken with the Spanish Authorities in order to establish frontier worker status in Spain.

As is the case with respect to persons working in Gibraltar as frontier workers, persons working in Spain as frontier workers are urged to ensure that they are registered with the relevant Spanish Authorities. This will enable them to continue to exercise EU rights in Spain in accordance with the Withdrawal Agreement. 


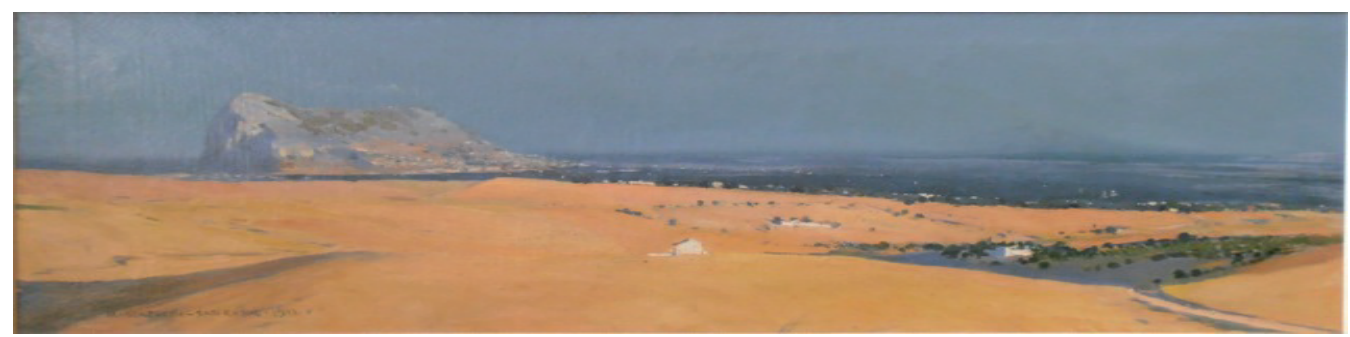

\section{Cuadernos de Gibraltar Gibraltar Reports}

\section{\#04 | 2020-2021}

Sumario

Table of Contents

\section{EDITORIAL}

Alejandro DEL VALLE GÁLVEZ; Inmaculada GONZÁLEZ GARCÍA, Gibraltar after the Brexit: Looking for a New and Imaginative Model of Cross-Border Cooperation in the EU Framework

\section{ESTUDIOS Y NOTAS}

Luis M. HINOJOSA MARTÍNEZ, Los movimientos de capital y los servicios financieros en las relaciones con Reino Unido y Gibraltar tras el Brexit: ¿Seguridad jurídica o ley de la selva?

Luis ROMERO BARTUMEUS, Las escalas de submarinos nucleares en Gibraltar y Rota, y los Planes de Emergencia Radiológica

Facundo D. RODRÍGUEZ, La cuestión de las Malvinas (Falklands) en el Cuarto Decenio Internacional para la Eliminación del Colonialismo

\section{ÁGORA}

Alejandro DEL VALLE GÁLVEZ, Creación de una AECT-Agrupación Europea de Cooperación Territorial- Campo de Gibraltar/Gibraltar (Guía breve sobre planteamiento, requisitos y procedimiento)

Alejandro GARCÍA HEREDIA, El Acuerdo Fiscal entre España y el Reino Unido en relación con Gibraltar

David CHEVASCO, Notes on Contemporary Bilingualism, Llanito and Language Policy in Gibraltar: a Study with a Present-day View of Linguistic Challenges

\section{DOCUMENTACIÓN}

Inmaculada GONZÁLEZ GARCÍA; Alejandro DEL VALLE GÁLVEZ; Lorena CALVO MARISCAL, Juan D. TORREJÓN RODRÍGUEZ:

Documentación I. Naciones Unidas - Gibraltar - Decisiones aprobadas por la Asamblea General de la ONU (2017-2019)

Documentación II. Brexit y Gibraltar - Tratado de Retirada, Protocolo, Tratado Fiscal y MOUs (2018-2020)

Documentación III. España, Brexit y Gibraltar. Declaraciones, Comunicados y Notas de Prensa (2018-2020)

Documentación IV. Andalucía, Brexit y Gibraltar (2018-2019)

Documentación V. Grupo Transfronterizo/Cross-Frontier Group, Memorándum de Entendimiento con el Gobierno de Gibraltar (2017) y Reglamento de Funcionamiento (2018)

Documentación VI. Principio de Acuerdo entre España y el Reino Unido sobre Gibraltar y sobre el Brexit, de 31.12.2020

Documentación VII. Mandato negociador para el Tratado entre el Reino Unido y la Unión Europea con respecto a Gibraltar, 5 de octubre de 2021

\section{LOS ARCHIVOS DE LUIS ROMERO BARTUMEUS}

La descolonización de Gibraltar, de CALVAR, J. - GUERITZ , E. J. - DEL CAMPO, S. - DAVIS H., Ed. Instituto de Cuestiones Internacionales, 1981, 110 páginas, por Luis ROMERO BARTUMEUS

Matar al Mensajero, Vivencias de un «Palomo» en Gibraltar, de TRIAY BOZZINO, J. J. - CASAUS BALAO, J. A., Ed. : Colecciones AUREA, 2000, 198 páginas, por Luis ROMERO BARTUMEUS

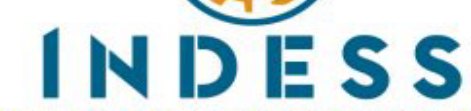

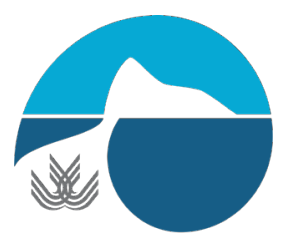

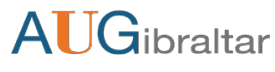

CÁTEDRA JEAN MONNET INMIGRACIÓN Y FRONTERAS DERECHO DE LA UNIÓN EUROPEA $\sim 2$

EDUCACIÓN DE LA UNIÓN EUROPEA

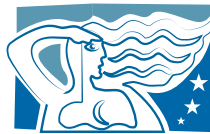

ESTUDIOS

INTERNACIONALES Y EUROPEOS

Centro de Estudios Internacionales y Europeos del Área del Estrecho 